\title{
PERANCANGAN APLIKASI JEJARING SOSIAL ALUMI PENCINTA APLIKSI BERBASIS ITC DENGAN ALGORITMA GRAPH BERBASIS WEB
}

\author{
Fitri Latifah', Imam Saefudin ${ }^{2}$ \\ Program Studi Komputerisasi Akutansi, AMIK BSI Jakarta ${ }^{1}$ \\ Program Studi Teknik Informatika, STMIK Nusa Mandiri Jakarta ${ }^{2}$ \\ fitri.flr@bsi.ac.id \\ imamsaefudin10@gmail.com
}

\begin{abstract}
ABSTRAK
Alumi adalah orang yeng telah tamat dari sekolah atau perguruan tinggi. Alumni STMIK Nusa Mandiri atau biasa disebut dengan IKANI memiliki peranan penting dalam menunjukkan pencitraan dan kualitas sebuah perguruan tinggi, karena wadah ikatan alumni itu bukan sekadar forum silaturahmi antar alumni saja, tetapi juga wadah untuk berdiskusi dan mengomunikasikan upaya dan usaha dalam memajukan perguruan tinggi. Dengan memanfaatkan fasilitas internet maka dibuat sebuah situs jejaring sosial untuk alumni STMIK Nusa Mandiri yang dapat mempermudah komunikasi antar para alumni. Komunikasi dengan menggunakan situs jejaring sosial dapat menumbuhkan rasa kebersamaan, keakraban dan keterikatan yang lebih kental jika dibandingkan dengan media komunikasi lain yang ada di Internet. Jejaring sosial yang dirancang bertujuan bukan hanya menghubungkan alumi dari STMIK Nusamandiri, khsusnya untuk Program Studi Teknik Informatika sebagai wadah bertukar informasi dan membentuk komunitas untuk mengembangka diri dengan tujuan memperkaya pengetahuan di bidang ITC dengan cara betujar informasi. Situs ini dibuat dengan memulai perancangan sistem terebih dahulu menggunakanan UML kemudian dilanjutkan dengan pembuatan user interface dan dengan menggunakan bahasa pemograman PHP dan MySQL sebagai manajemen basis data. Situs ini masih memiliki beberapa kekurangan baik dari segi fitur maupun keamanan.
\end{abstract}

Kata kunci : Jejaring Sosial, Alumni Teknik Informatika STMIK Nusa Mandiri, berbasis web, Berbasis ITC, bahasa pemrograman PHP

\begin{abstract}
Alumni is a person who finished their studi from colege or university. Alumni STMIK Nusa Mandiri or commonly referred to as IKANI has an important role in showing the imaging and quality of a university, because the alumni container is not just a forum of friendship between alumni, but also a container to counsel and communicate efforts and efforts in advancing university. By utilizing the internet facility then created a social networking site for alumni STMIK Nusa Mandiri which can facilitate communication between the alumni. Communicating using this site can make friendship and knowledge in teh ITC, become closer than other site which already axist in Internet. This site was created by starting the first system design using UML then continued with the creation of user interface and by using programming language PHP and MYSQL as database management. The site still has some disadvantages in terms of both features and security.
\end{abstract}

Keyword : social networking, Alumni Teknik Informatika STMIK Nusa Mandiri, web programming, ITC base, PHP Language 


\section{JURNAL PETIR}

Vol. 11, No. 2, September 2018, P-ISSN 1978-9262, E-ISSN 2655-5018

\section{PENDAHULUAN}

Interaksi antar manusia yang melibatkan komunikasi merupakan sesuatu hal yang alamiah yang terjadi di antara manusia. Komunikasi tersebut digunakan untuk saling berhubungan agar penyampaian suatu informasi dapat tersampaikan dengan baik dan jelas. Jejaring sosial merupakan sebuah struktur sosial yang mamberikan kesempatan kepada pengguna untuk memperluas hubungan sosial. Tingginya pengguna jejaring yang bahkan tidak dapat dibatasi cakupannya, dapat dijadikan sebuah kesempatan untuk mempermudah hubungan yang dibutuhkan oleh sebuah organisasi tertentu.

Menurut Ardiartoro dkk (2016:42) bahwa Situs jejaring sosial merupakan salah satu bentuk media sosial yang bisa digunakan untuk berkomunikasi. Situs jejaring sosial yang pada awalnya digunakan untuk tujuan pertemanan (mencari, menemukan dan menambah teman) kini telah dapat digunakan sebagai media untuk berkomunikasi. Komunikasi dengan menggunakan situs jejaring sosial dapat menumbuhkan rasa kebersamaan, keakraban dan keterikatan yang lebih kental jika dibandingkan dengan media komunikasi lain yang ada di Internet.

Sebagai bahan objek penelitian ini adalah Sekolah Tinggi Manajemen Informatika dan Komputer (STMIK ) Nusa yang memiliki 2 Program Studi Sarjana Strata Satu (S1) yaitu Teknik Informatika dan Sistem Informatika serta memiliki alumni yang terus bertambah setiap tahunnya seiring dengan tingkat kelulusan yang semakin meningkat.

Dengan semakin bertambahnya jumlah alumni maka dirasakan ada kebutuhan akan sarana untuk berkumpulnya alumni, di mana para alumni tersebut telah dipisahkan oleh jarak sehingga dibutuhkan sebuah media untuk dapat berinteraksi dengan alumni lain yang dapat digunakan oleh para alumni dalam membantu alumni yang lain nya untuk tetap terhubung dengan kampus dimana mereka pernah belajar dan menimba ilmu selain dari itu media sosial ini di bentuk sebagai wadah bagi komunitas mencinta aplikasi berbasis ITC untuk bertukar informasi dan menjadi sumber bagi para adik kelasnya untuk mendapatkan pengetahuan tentang aplikasi berbasis ITC yang berkembang.

Pembuatan jejaring sosial masih dikhususkan bagi jurusan Teknik Informatika STMIK Nusa Mandiri dengan tujuan sebagai wadah penghubung komunikasi antara para alumni agar tetap bisa saling berkomunikasi, bertukar berita, dan sebagai wadah komunitas pencinta aplikasi berbasis ITC untuk menambah pengetahuan bagi alumni itu sendiri maupun bagi adik kelasnya yang masih belajar di kampus STMIK Nusamandiri.

\section{LANDASAN TEORI}

\section{A. Teori Graph}

Graph merupakan sebuah diagram alir yang terdiri dari simpul (node/vertex) dan sisi (egde), teori graph adalah teori yang dapat digunakan untuk merepresentasikan objek diskrit. Teori graph untuk pertamakalinya dipekenalkan pada abad ke 18 oleh seorang matematikawan bernama Leonahard Euler.

Graph dapat digambarkan pada sekumpulan simpul yang dihubungkan dengan sisi yang merupakan hubungan antara semua simpul. Graph merupakan himpunan dari $(\mathrm{V}<\mathrm{E})$ dimana $\mathrm{V}$ bukanlah himpunan kosong dari simpul-simpul $\mathrm{V}=(\mathrm{v} 1, \mathrm{v} 2, \mathrm{v} 3, \mathrm{v} 4 \ldots \mathrm{vn})$ dan $\mathrm{E}$ merupakan himpunan sisi yang mengubungkan antara simpul dengan yang lain $\mathrm{E}=(\mathrm{e} 1, \mathrm{e} 2, \mathrm{e} 3, \mathrm{e} 4 \ldots \mathrm{en})$, sehingga graph $\mathrm{G}$ dapat dinotasikan dengan singkatan yaitu $\mathrm{G}=(\mathrm{V}, \mathrm{E})$

\section{B. Jejaring Sosial}

Social Networking ( Jejarng Sosial) merupakan studi yang mempelajari hubungan dengan memanfaatkan teori graph, Jejaring sosial adalah teknik yang digunakan untuk mempelajari hubungan/relasi antar anggota dari sebuah kelompok Hanneman A.R Ridle (2005) dalam teori jejaring sosial terdiri dari simpul dan hubungan yang dapat berupa garis, tepi, link atau sambungan. Simpul digambarkan sebagai individu sedangkan garis adalah hubungan antar para individu 


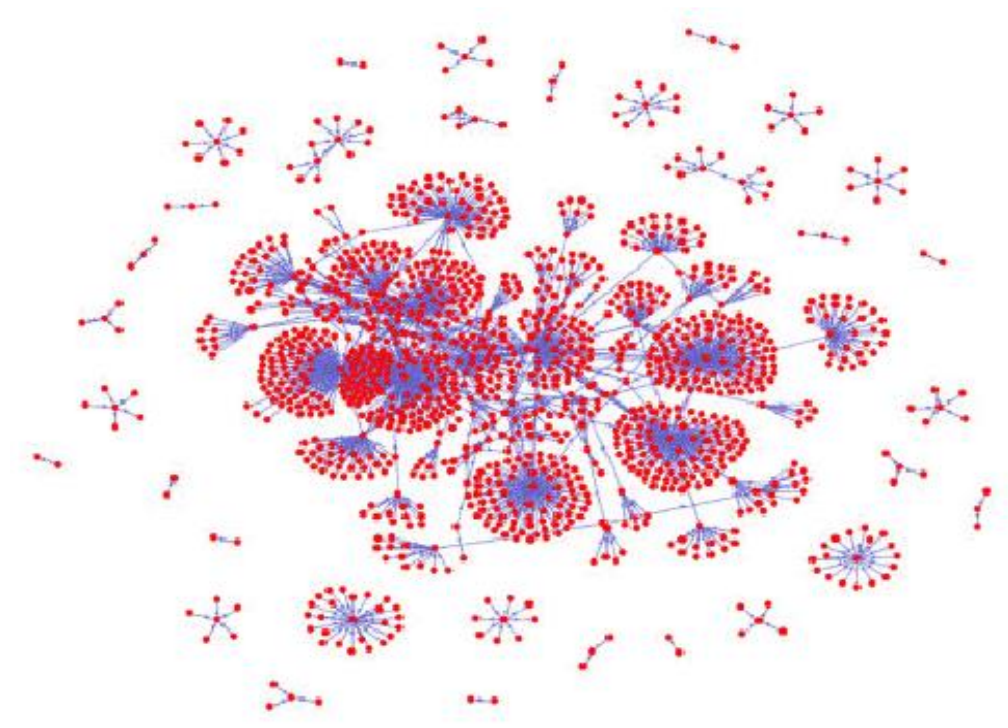

Dikutip dari : Kazienko, P. \& Musial, K. (2005). Social Networks. (http://www.ii.pwr.wroc.pl/ kazienko/pub/2005/social\%20networks.pdf)

Sumber : Budi Susanto (200..)

Menurut Putra (2014) jejaring sosial adalah sebuah struktur sosial yang dibentuk dari simpulsimpul (yang umumnya adalah individu atau organisasi) yang dijalin dengan satu atau lebih tipe relasi spesifik seperti nilai, visi, ide, teman, keturunan, dll. Jejaring sosial bisa diartikan sebagai sarana pemersatu antara individu satu dengan individu yang lain sehingga menjadi sebuah sosial yang saling berkaitan (berinteraksi) satu sama lain.

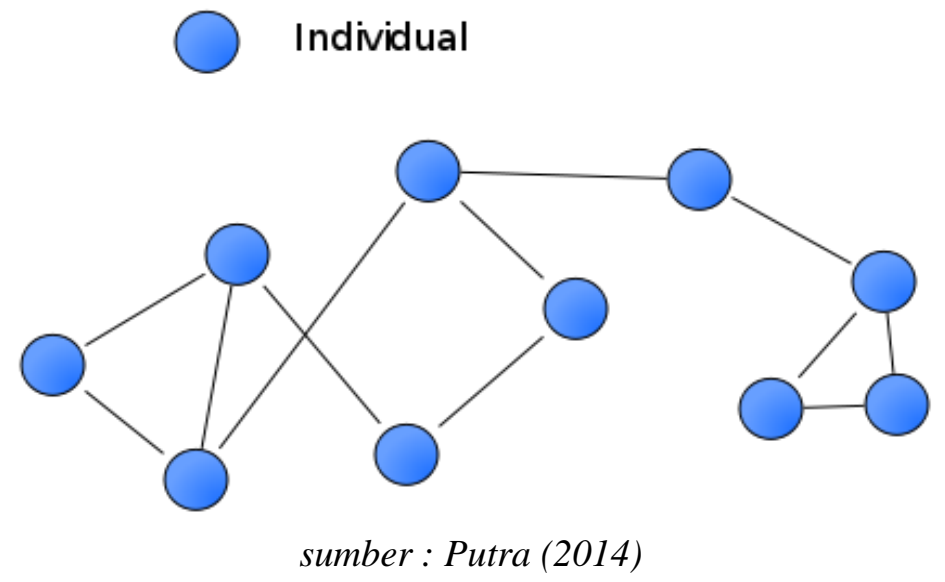

Gambar 2.2. Individu (bola) saling berhubungan satu sama lain membentuk sebuah hubungan satu sama lain

Analisis jaringan jejaring sosial memandang hubungan sosial sebagai simpul dan ikatan. Simpul adalah aktor individu di dalam jaringan, sedangkan ikatan adalah hubungan antar aktor tersebut. Bisa terdapat banyak jenis ikatan antar simpul. Penelitian dalam berbagai bidang akademik telah menunjukkan bahwa jaringan jejaring sosial beroperasi pada banyak tingkatan, mulai dari keluarga hingga negara, dan memegang peranan penting dalam menentukan cara memecahkan masalah, menjalankan organisasi, serta derajat keberhasilan seorang individu dalam mencapai tujuannya. 


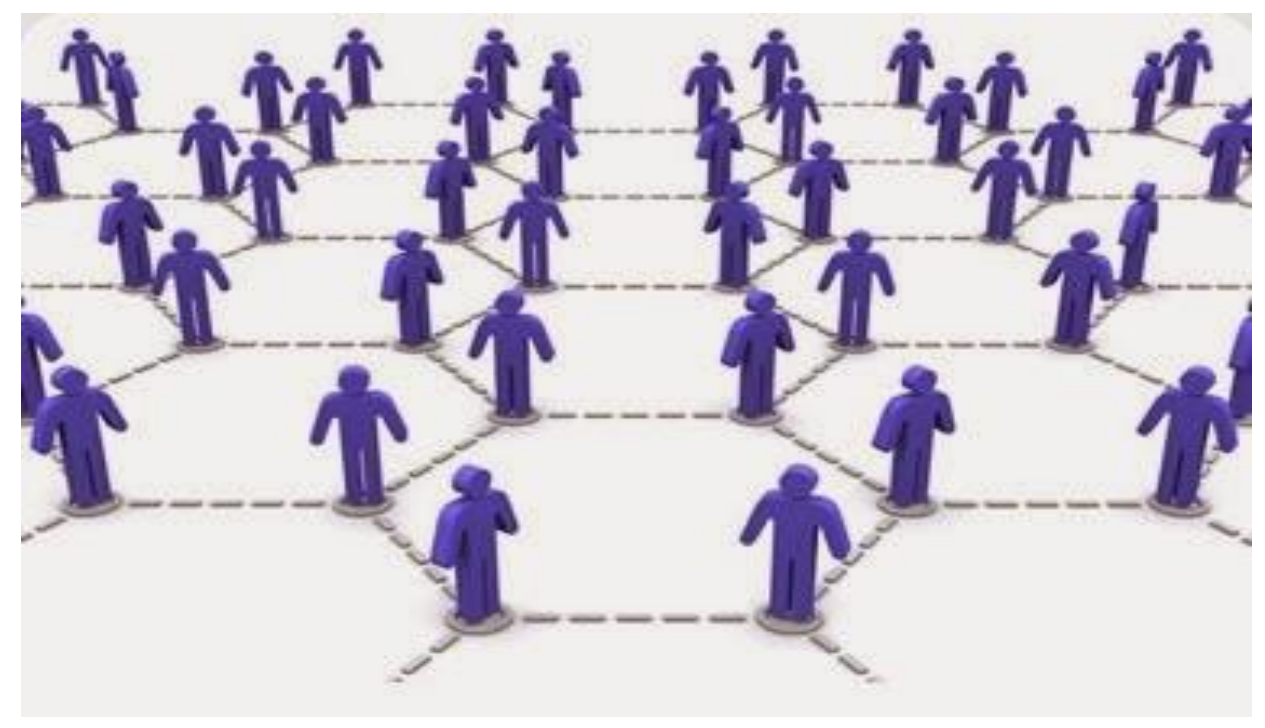

sumber : Putra (2014:4)

Gambar 2.3. Jejaring sosial mampu menghubungankan individu satu dengan yang lain

Gambar 2.3 menjelaskan tentang kemampuan jejaring sosial dalam kehiudupan manusia. Bisa dilihat dengan jelas oleh kita semua bahwa jejaring sosial mampu membuat manusia saling berhubungan walaupun jarak jauh dan menghasilkan sebuah sosial sehingga manusia dapat mengenal satu sama lain.

Kumpulan dari individu disebut dengan komunitas. Komunitas ini terbentuk karena kebiasaan individu berinteraksi dengan individu lain kemudian muncul sebuah kumpulan individu yang saling berinteraksi.

Banyak manfaat yang bisa diambil dari jejaring sosial. Manfaat nyatanya dalam kehidupan sehari-hari yaitu mempunyai banyak teman akrab. Manusia disebut sebagai makhluk sosial, sebutan ini dikemukakan karena manusia tidak bisa hidup sendiri, manusia memerlukan bantuan dari orang lain. Untuk itu, manusia perlu bersosialisasi sehingga dibuatlah sebuah jejaring sosial untuk mendukung kehidupan manusia sebagai makhluk sosial.

Dalam bentuk yang paling sederhana, suatu jaringan jejaring sosial adalah peta semua ikatan yang relevan antar simpul yang dikaji. Jaringan tersebut dapat pula digunakan untuk menentukan modal sosial aktor individu. Konsep ini sering digambarkan dalam diagram jaringan sosial yang mewujudkan simpul sebagai titik dan ikatan sebagai garis penghubungnya.

\section{Website}

Menurut Hidayat (2010:6) Website adalah keseluruhan halaman-halaman web yang terdapat dalam sebuah domain yang mengandung informasi. Sebuah website biasanya dibangun atas banyak halaman web yang saling berhubungan. Jadi dapat dikatakan bahwa, pengertian website adalah kumpulan halaman-halaman. yang digunakan untuk menampilkan informasi teks, gambar diam atau gerak, animasi, suara, dan atau gabungan dari semuanya, baik yang bersifat statis maupun dinamis yang membentuk satu rangkaian bangunan yang saling terkait, yang masing-masing dihubungkan dengan jaringan-jaringan halaman. Hubungan antara satu halaman website dengan halaman website lainnya disebut dengan hyperlink, sedangkan teks yang dijadikan media penghubung disebut hypertext.

Situs website di kategorikan menjadi 2 yaitu website statis dan website dinamis, website statis adalah website yang berisi atau menampilkan informasi - informasi yang sifatnya tetap (statis), sedangkan website dinamis adalah website yang menampilkan informasi serta dapat berinteraksi dengan user. 


\section{UML (Unifield Modelling Language)}

Menurut Widodo dan Herlawati (2011), bahwa beberapa literature menyebutkan bahwa UML menyediakan sembilan jenis diagram, yang lain menyebutkan delapan karena ada beberapa diagram yang digabung, misanya diagram komunikasi, diagram urutan dan diagram pewaktuan digabung menjadi diagram interaksi.

Menurut Sukamto dan M. Shalahudin (2014), UML hanya berfungsi untuk melakukan pemodelan. Jadi penggunaan UML tidak terbatas pada metodologi tertentu, meskipun pada kenyataannya UML paling banyak digunakan pada metodologi berorientasi objek.

\section{E. Use Case Diagram}

Menurut Sukamto dan M. Shalahudin (2014), Use case atau diagram use case merupakan pemodelan untuk kelakuan (behavior) sistem informasi yang akan dibuat. Use case mendeskripsikan sebuah interaksi antara satu atau lebih aktor dengan sistem informasi yang akan dibuat. Secara kasar, use case digunakan untuk mengetahui fungsi apa saja yang ada di dalam sebuah sistem informasi dan siapa saja yang berhak menggunakan fungsi-fungsi itu.

\section{F. Activity Diagram}

Sukamto dan M. Shalahudin (2014), diagram aktivitas atau activity diagram menggambarkan workflow (aliran kerja) atau aktivitas dari sebuah sebuah sistem atau proses bisnis atau menu yang ada pada perangkat lunak. Yang perlu di perhatikan disini adalah bahwa diagram aktivitas menggambarkan aktivitas sistem bukan apa yang dilakukan aktor, jadi aktivitas yang dapat dilakukan oleh sistem.

\section{G. ERD (Entity Relationship Diagram)}

Menurut Sutanta (2011:91), Entity Relationship Diagram (ERD) merupakan suatu model data yang dikembangkan berdasarkan objek." Entity Relationship Diagram (ERD) digunakan untuk menjelaskan hubungan antar data dalam basis data kepada pengguna secara logis. Entity Relationship Diagram (ERD) didasarkan pada suatu persepsi bahwa real world terdiri atas obyekobyek dasar tersebut. Penggunaan Entity Relationship Diagram (ERD) relatif mudah dipahami, bahkan oleh para pengguna yang awam. Bagi perancang atau analis sistem, Entity Relationship Diagram (ERD) berguna untuk memodelkan sistem yang nantinya, basis data akan di kembangkan. Model ini juga membantu perancang atau analis sistem pada saat melakukan analis dan perancangan basis data karena model ini dapat menunjukkan macam data yang dibutuhkan dan kerelasian antar data didalamnya.

\section{METODOLOGI PENELITIAN}

\section{a. Metode Pengumpulan Data}

Dalam Pengembangan Aplikasi dalam mengumpulkan data, peneliti menggunakan metode

1. Obvervasi

Peneliti melakukan observai keberbagai sumber untuk memastikan navigasi - navigasi apa yang dibutuhkan dalam perancangan aplikasi jejaring sosial alumni ini

2. Wawancara

Menggali informasi khusus nya kepada alumni dan mahasiswa STMIK Nusamandiri mengenai isi dari apliasi agar dapat digunakan bukan saja sebagai ajang silaturahmi akan tetapi dapat menjadi wadah bagi komunitas pencinta aplikasi bagi alumni yang akan bergabung

3. Studi Pustaka

Melakukan tinjauan pustak untuk mendaptkan informasi yang berkaitan dengan apliasi tentang jejaring sosial melalui buku atau sumber refernsi lainnya yang mendukung dalam penelitian ini 


\section{JURNAL PETIR}

Vol. 11, No. 2, September 2018, P-ISSN 1978-9262, E-ISSN 2655-5018

\section{b. Rancangan Pembangunan Aplikasi}

Dalam penelitian ini, penulisan menggunakan metode wterfall untuk membuat desain aplikasi jejaring sosial dengan alasan penggunaan metode ini karena merupakan metode yang sistematik dan sekuensila (Rosa\&Shalahuddin, 2013), dimana tahapan pembuatan aplikasi dengan metode ini terdiri dari :

1. Analisa

Dalam tahapan ini yang dikerjakan adalah melakukan analisa kebutuhan aplikasi yang dilakukan oleh peneliti dalam mengumpulkan data untuk merancang aplikasi

2. Desain

Pada proses ini merupakan proses multi langkah dimana berfokus pada rancangan aplikasi yang meliputi perancangan algoritma, perancangan database, rancangan permodelan dengan menggunakan UML, proses ini juga merupakan proses penterjemahan hasil analisa ke dalam mereprestasikan perangkat lunak

3. Code

Dalam tahapan ini adalah proses penterjemahan desaiin kedalam code untuk mengimplemetasikan hasil dari model desain

4. Test

Setelah tahap pencodean (Coding) adalah melakukan pengujian aplikasi untuk mengetahui kesesuaian input dengan hasil atau ouput dengan kebutuhan yang telah drancang pada tahap sebelumnya.

5. Support

Pada tahap ini dilakukan pemrosesan dari coding yang dibuat pada perangkat yang memiliki spesifikasi yang disesuaikan dengan desain yang telah dibutuhkan

\section{HASIL DAN ANALISA SISTEM}

\section{Spesifikasi Dokumen Sistem}

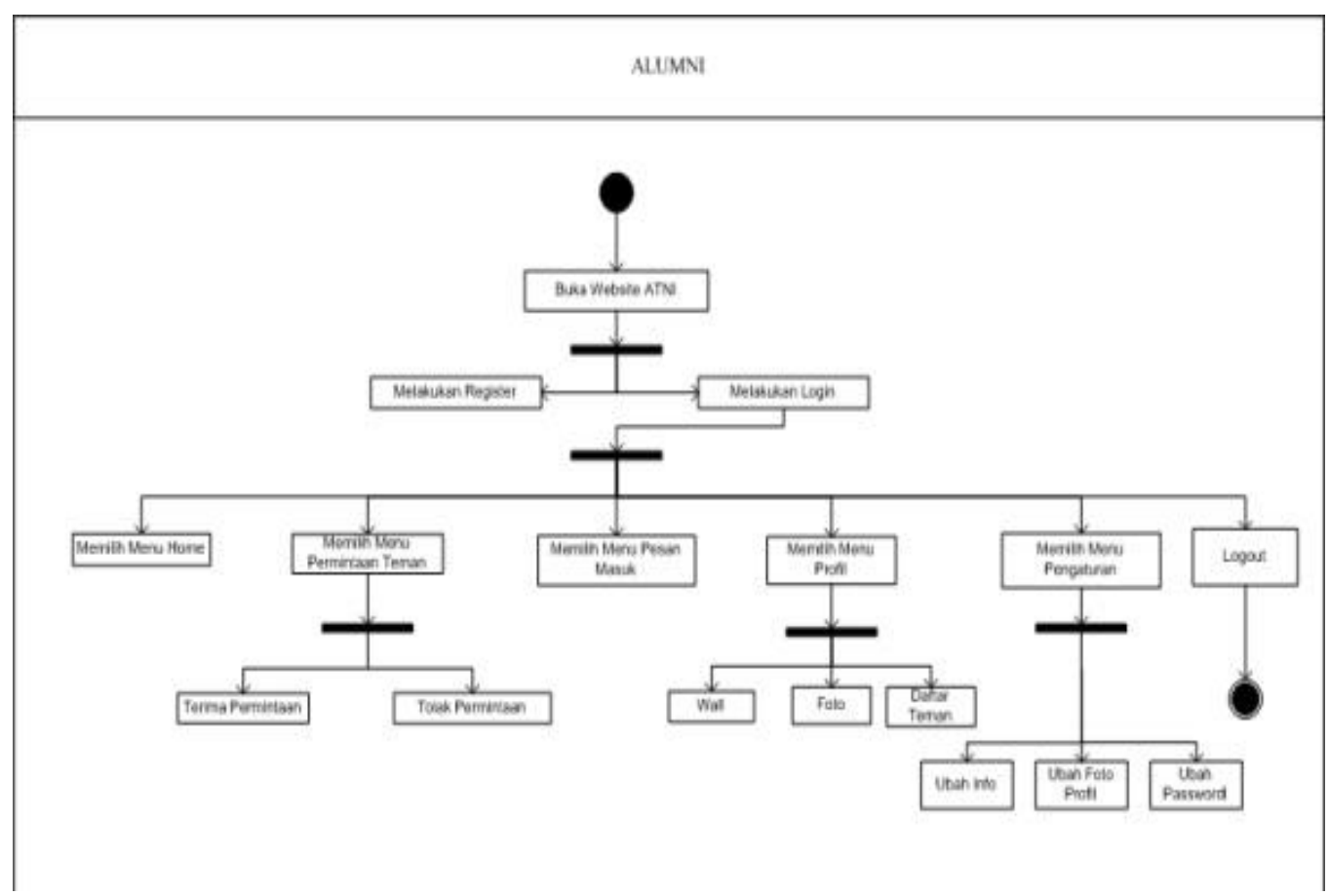

Sumber : Hasil Pengolahan (2017)

Gambar 3.3. Activity Diagram Sistem Berjalan 


\section{Analisa Kebutuhan Software}

\section{a. Tahap Analisis}

Halaman Admin :

A1. Admin dapat melakukan login

A2. Admin dapat mengelola user

A3. Admin dapat menghapus user

A4. Admin dapat mengolah status dan Komentar user

A5. Admin dapat menambah Admin

A6. Admin dapat melakukan logout

Halaman user:

B1. User harus melakukan pendaftaran akun terlebih dahulu

B2. User dapat melakukan login

B3. User dapat mengolah data profil

B4. User dapat menambahkan teman

B5. User dapat mengolah status

B6. User dapat mengunggah foto

B7. User dapat menberikan komentar

B8. User dapat membuat private message

B9. User dapat melakukan chatting

B10. User dapat mengubah password

B11. User dapat melakukan logout

\section{b. Use Case}

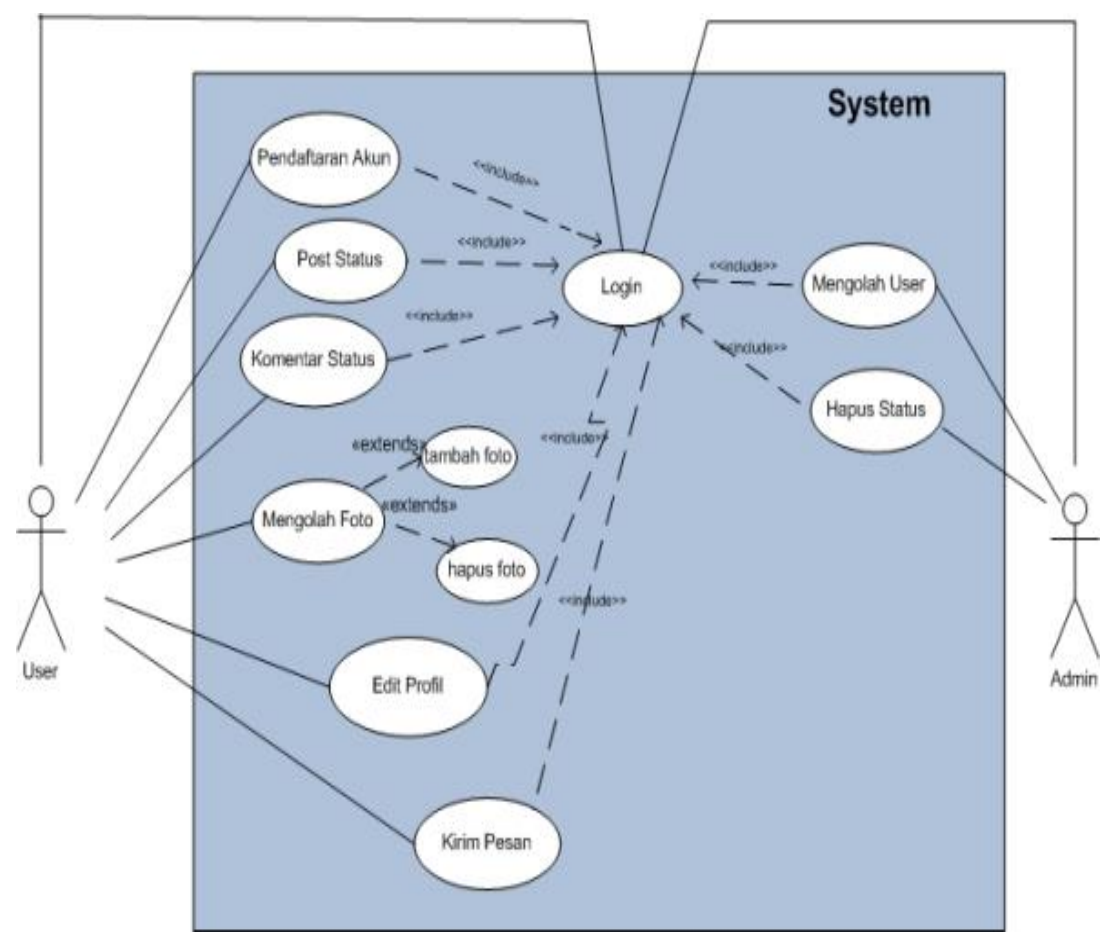

Sumber : Hasil Pengolahan (2017)

Gambar 4.1. Use Case Diagram Jejaring Sosial Alumni Teknik Informatika STMIK Nusa Mandiri 


\section{c. Activity Diagram}

Diagram Pendaftaran Akun

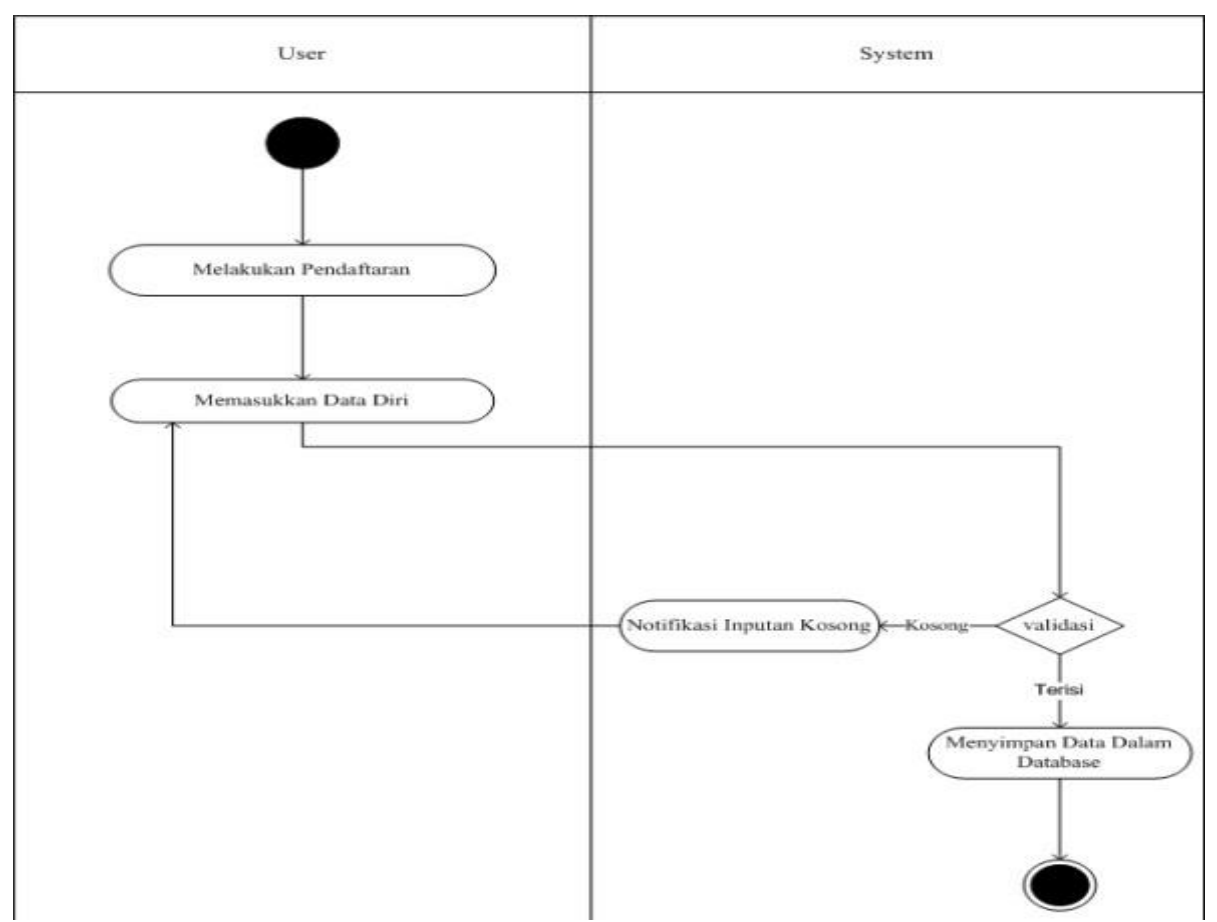

Gambar 4.2. Activity Diagram Pendaftaran Akun

\section{d. Entity Relationship Diagram (ERD)}

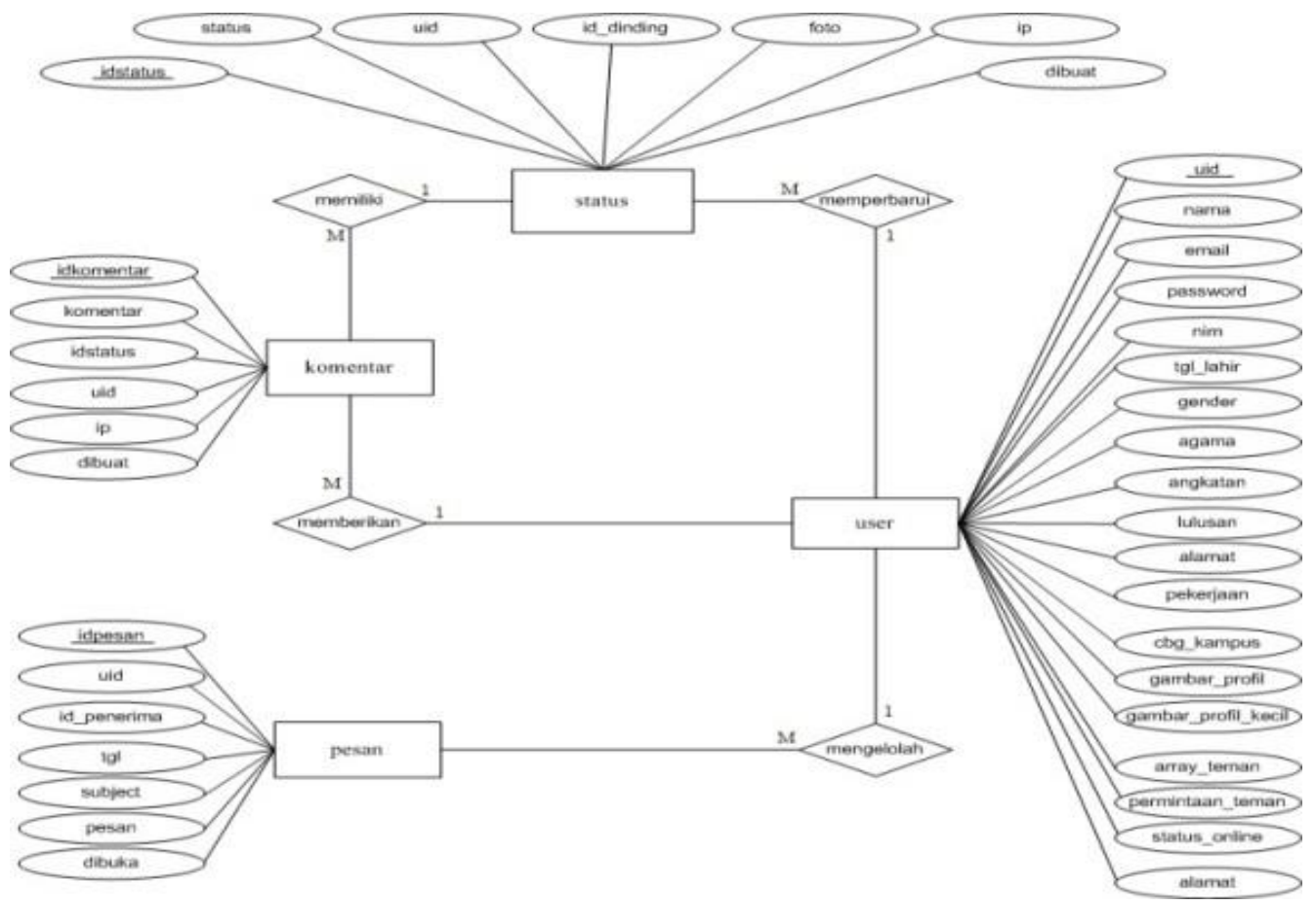

Sumber : Hasil Pengolahan (2017)

Gambar 4.12. ERD Jejaring Sosial Alumni 
e. LRS (Logical Relational Strukture)

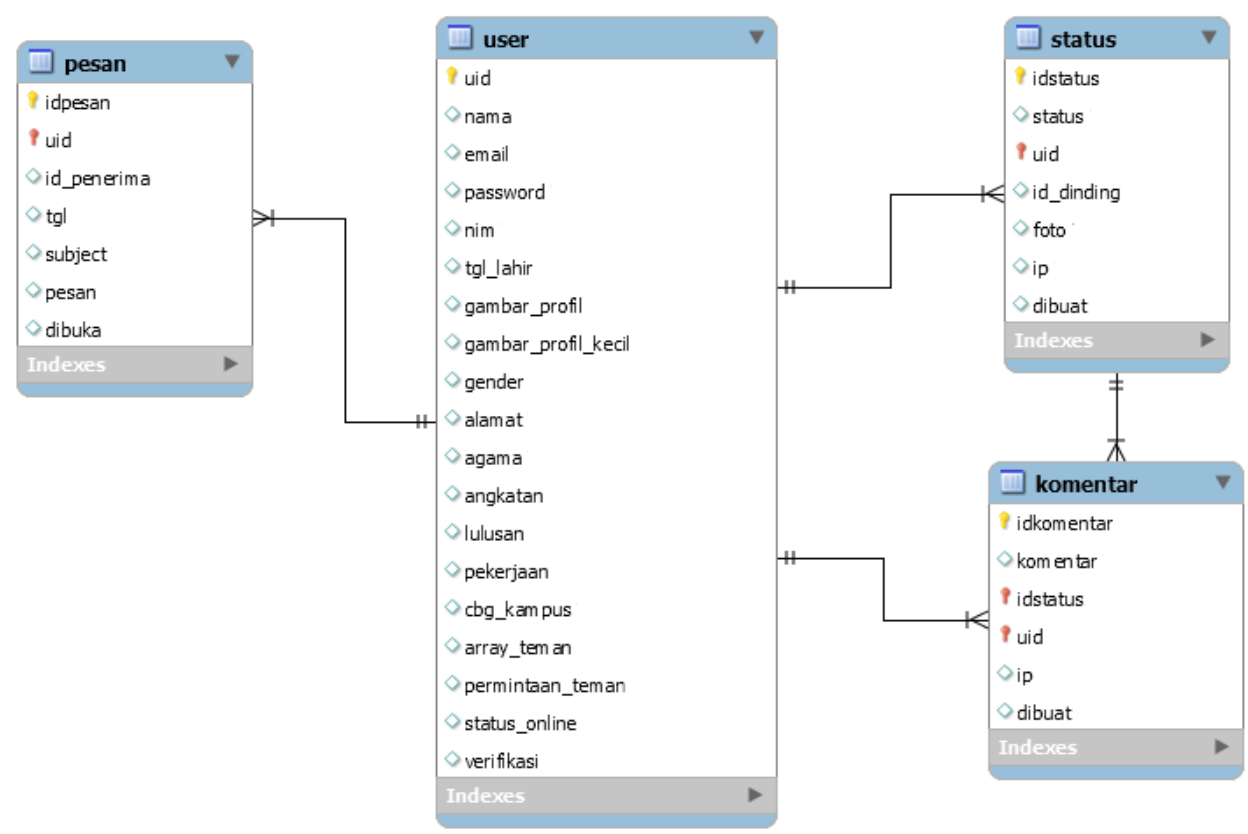

Sumber : Hasil Pengolahan (2017)

Gambar 4.13. LRS (Logical Relational Structure)

\section{f. Deployment Diagram}

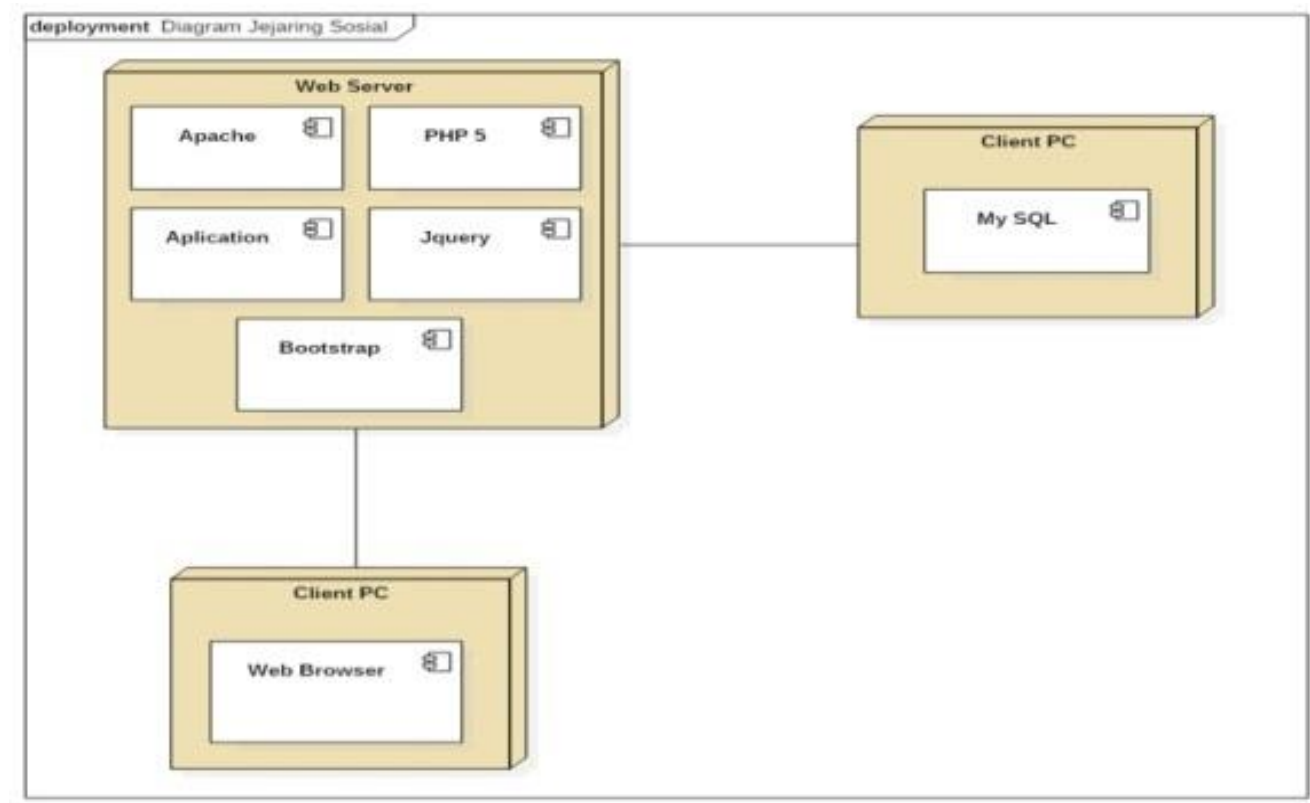

Sumber : Hasil Pengolahan (2017)

Gambar 4.14. Deployment Diagram pada situs Jejaring Sosial Alumni 


\section{g. Component Diagram}

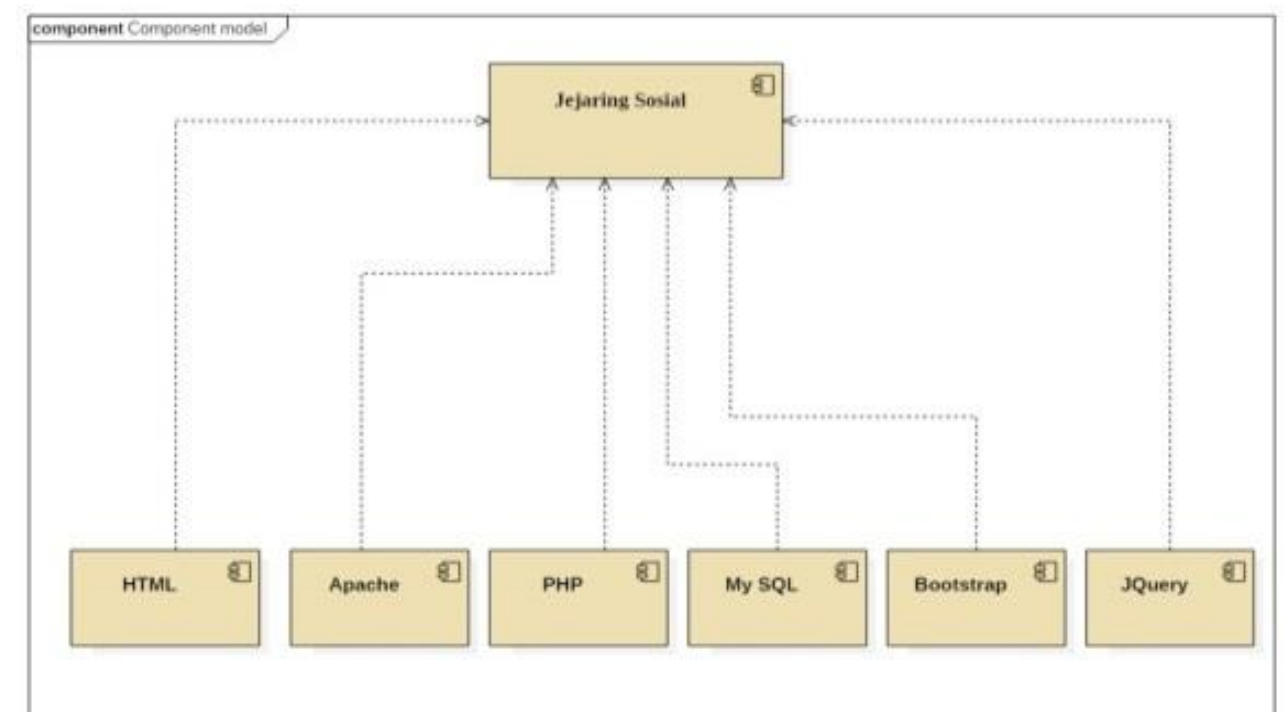

Sumber : Hasil Pengolahan (2017)

Gambar 4.15. Component Diagram pada situs Jejaring Sosial

\section{Implementasi}

1. Tampilan Halaman Login dan Register

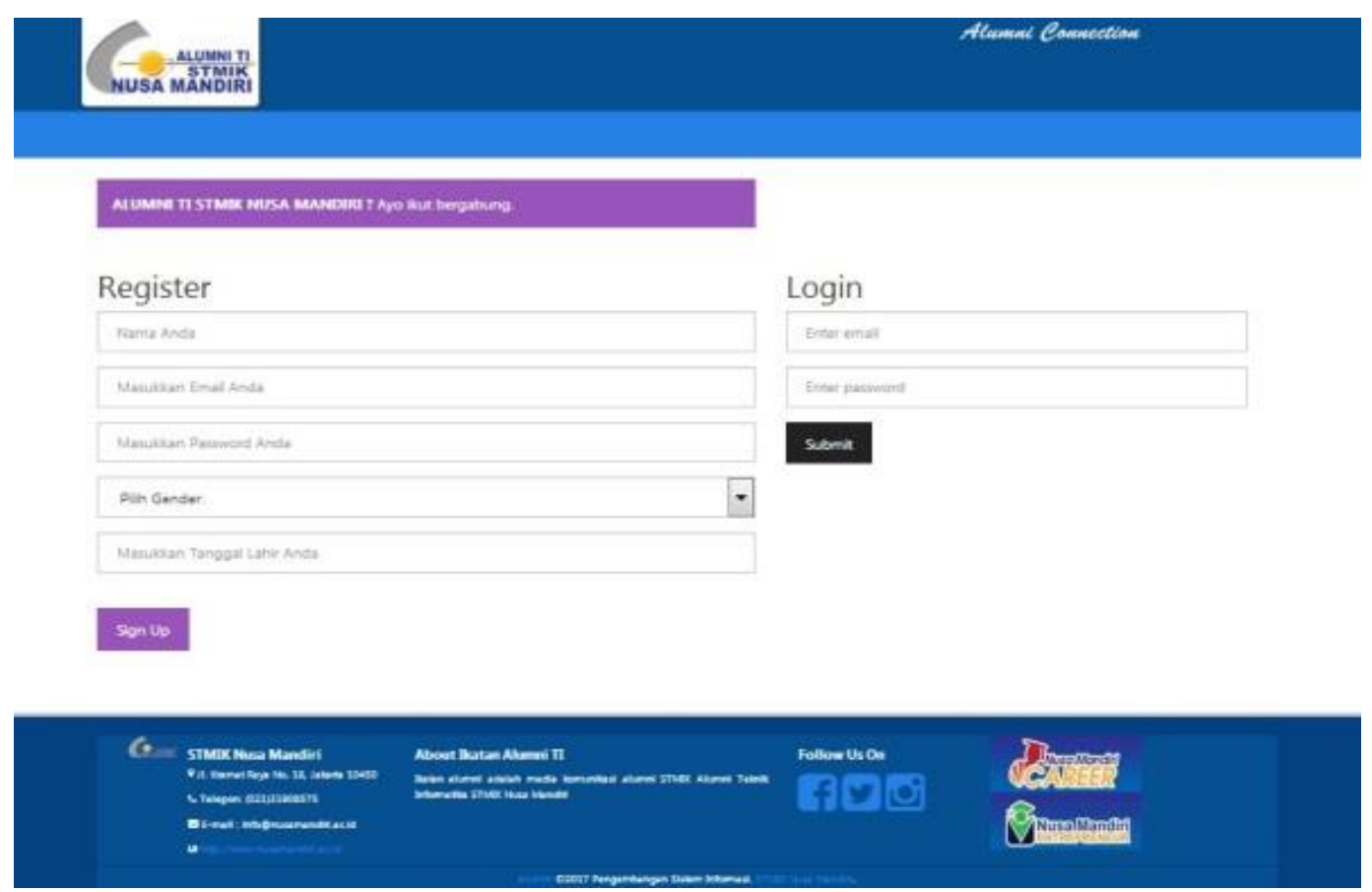

Sumber : Hasil Pengolahan (2017)

Gambar 4.16. Tampilan Halaman Login dan Register 


\section{Tampilan Halaman Beranda}
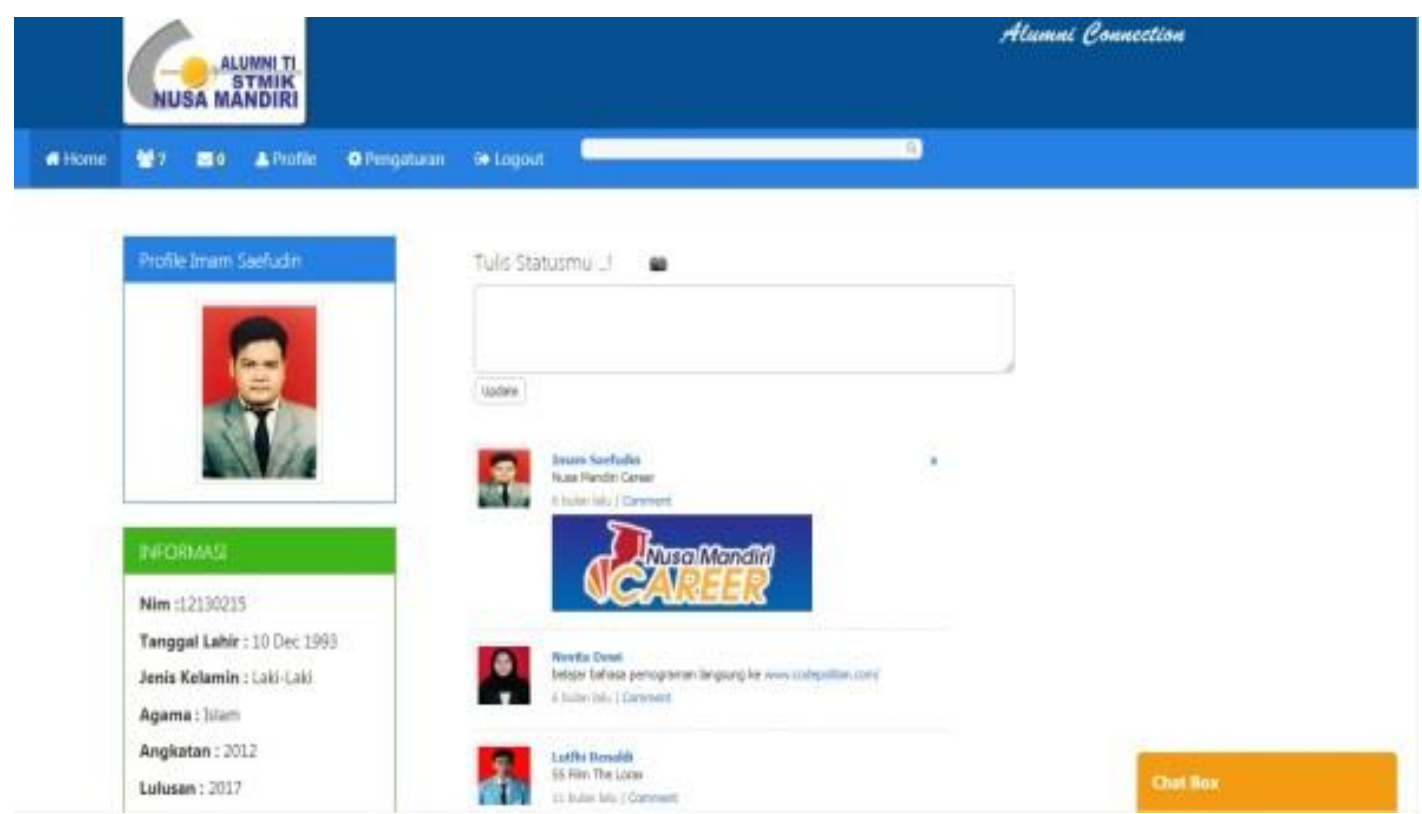

Sumber : Hasil Pengolahan (2017)

Gambar 4.17. Tampilan Halaman Beranda

\section{Tampilan Halaman Profil}
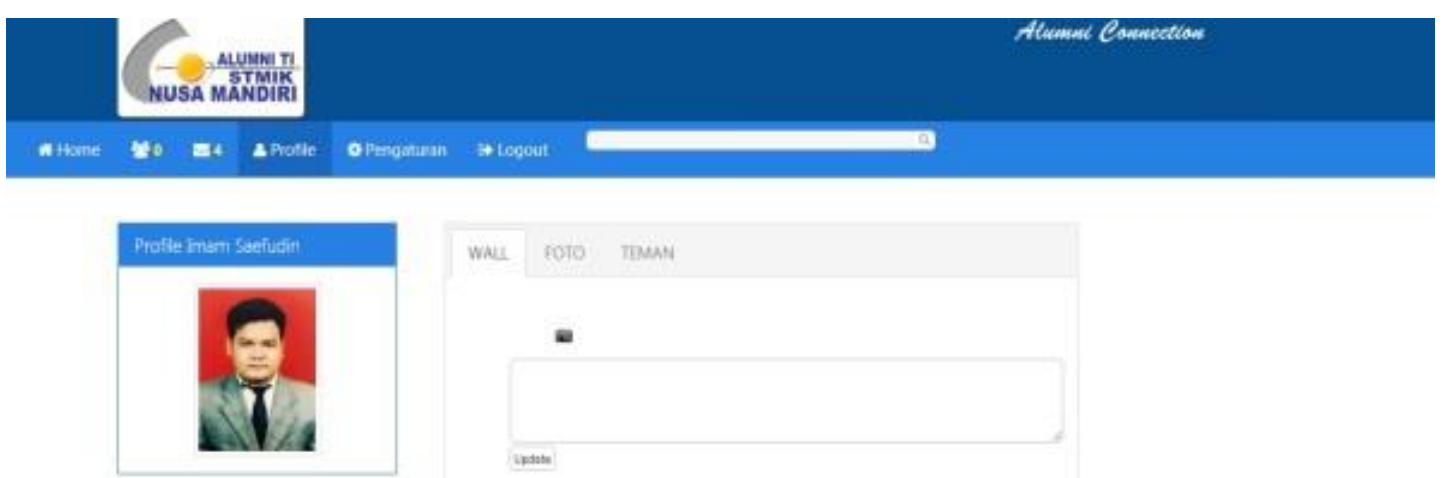

\begin{tabular}{|c|}
\hline PGFOAMASI \\
\hline $\operatorname{Nim}: 12130215$ \\
\hline Tanggal Lahir : 10 Dec 1993 \\
\hline Jensis Kelamin : Labs Lâk \\
\hline Apama : Islam \\
\hline Angkatan : 2012 \\
\hline Lelusan : 2017 \\
\hline
\end{tabular}

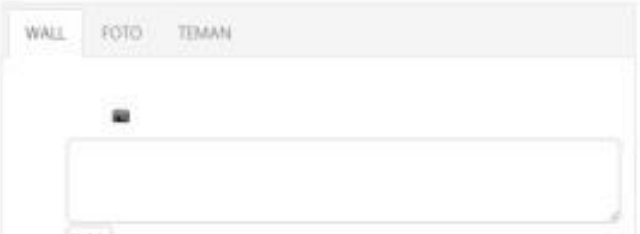

untas

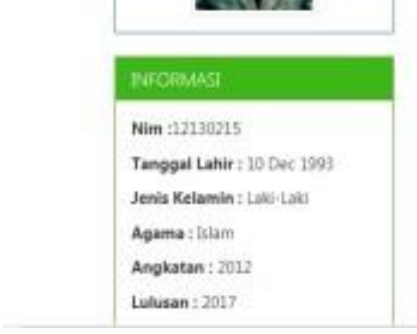

Sumber : Hasil Pengolahan (2017)

Gambar 4.20. Tampilan Halaman Profil 


\section{JURNAL PETIR}

Vol. 11, No. 2, September 2018, P-ISSN 1978-9262, E-ISSN 2655-5018

\section{PENUTUP}

\section{Kesimpulan}

Berdasarkan dari penelitian yang telah dilakukan maka dapat disimpulkan bahwa:

1. Perancangan aplikasi jejaring sosial dapat di bangun dengan menggunakan algoritma graph

2. Dengan adanya situs jejaring sosial maka alumni dapat dimanfaatkan oleh alumni untuk bertukar informasi dan menjalin silaturahmi, sebagai ajang untuk menginformasikan kebutuhan akan skill yang dibutuhkan perusahaan, selain dari itu dapat menjadi wadah komunitas pencinta aplikasi berbasis ITC

3. Dengan adanya situs jejaring sosial maka akan membantu STMIK Nusa Mandiri untuk melakukan proses pendataan terhadap alumni.

\section{Saran}

Agar kedepannya situs ini menjadi lebih baik maka disarankan untuk menambahkan fitur upload video, fitur grup, konektivitas, dibuatkan lagi navigator untuk dimanfaatkan sebagai wadah komunitas pencinta aplikasi agar dapat dimanfaatkan untuk menambah pengetahuan bagi yang ingin meambah pengetahuan tetnag aplikasi-aplikasi yang sedang up to date ke jejaring sosial lainnya, geolocation dan dapat berjalan pada platform mobile pada situs jejaring sosial alumni STMIK Nusa Mandiri.

\section{DAFTAR PUSTAKA}

Ardiartoro ,Frandita Agustino, Wawan Laksito YS \& Teguh Susyanto. 2016. PembuatanSitus Social Network Untuk Mahasiswa Dan Dosen Di STMIK Sinar Nusantara Surakarta Menggunakan Ajak, PHP DAN MYSQL Dalam Intranet Di Lingkungan STMIK Sinar Nusantara Surakarta. ISSN : 2338-4018. Vol 4, No 1 (2016). Diambil dari

http://p3m.sinus.ac.id/jurnal/index.php/TIKomSiN/article/view/244.).

Budayasa, Ketut. 2007. Teori Graph dan Aplikasinya. Surabaya: Unesa University PressSurabaya.

Hidayat, Rahmat. (2010). Cara Praktis Membangun Website Gratis : Pengertian Website. Jakarta : PT Elex Media Komputindo Kompas, Granedia

Juliandatu Masido, Nurio, Pengaplikasian Graf dalam kehidupan sehari -hari, makalash

Manalu, Mamed Rofendy .2014. Perancangan Jejaring Sosial Berbasis Web Pada GBI SUNGGAL MEDAN. ISSN : 2088-3943. Medan : Jurnal Mantik Penusa Vol 16 No 2 Desember 2014.

Putra, Ega Dewa. 2014. Menguak Jejaring Sosial. Ebook. Diambil dari : http://125.160.17.21/speedyorari/view.php?file=ebook/ebook-SU2013/SuryaUniv-MenguakJejaringSosial.pdf

Pranatha, Made Doddy Adi.2015. Situs Jejaring Sosial Alumni STIKOM BALI Berbasis Web Dengan Menggunakan .Net Framework. Diambil dari : http://ejournal.stikombali.ac.id/index.php/knsi/article/view/408

Rosa, A. S., \& Shalahuddin, M. (2013). Rekayasa perangkat lunak terstruktur dan berorientasi objek. Bandung: Informatika.

Satyanugraha, Dadun, Penerapan Teori Graf Dalam Renacan Tata Ruang Kota, Makalah Matematika Diskrit, 2016, http://informatika.stei.itb.ac.id/ rinaldi.munir/Matdis/20152016/Makalah-Matdis-2015/Makalah-IF2120-2015-112.pdf

Sukamto, Rosa Ariani dan M. Shalahuddin.2014. Rekayasa Perangkat Lunak Terstruktur dan Berorientasi Objek. Bandung: Informatika

Sutarman. 2009. Pengantar teknologi Informasi. Jakarta : Bumi Aksara. 
Sutanta, Edhy. 2011. Basis Data Dalam Tinjauan Konseptual. Yogyakarta : Andi Offset.

Shaffer, Clifford, Data Structure and Algorithm Analy, Departement of Computer Science Virginia Tech Blacksburg.VA, 2012

Sjukani, Moh, Struktur Data (Algoritma \& Struktur Data 2 ) dengan C,C++, Edisi 3, 2009, Mitra Wacana Media, Jakarta

Wibisono, Samuel, Matematika Diskrit, edisi 2, 2008, Graha Ilmu, Yogyakarta

Widodo, Prabowo Pudjo dan Herlawati. 2011. Menggunakan UML. Bandung : Informatika

Wirdasari, Dian, Teori Graph dan Implemetasinta dalam ilmu komputer, jurnal Saintikom, vol. 10/no.1/Januari 2011. https://prpm.trigunadharma.ac.id/public/fileJurnal/hpiM4-Jurnal-DWTeoriGraph.pdf 